\title{
Regio- and enantioselective reduction of a $\alpha$-methyleneketone by Rhodotorula glutinis
}

\author{
Gelson J. Andrade Conceição, * Paulo J. S. Moran, and J. Augusto R. Rodrigues* \\ Universidade Estadual de Campinas, Instituto de Química, CP 6154, 13084-971, \\ Campinas-SP, Brazil \\ E-mail: jaugusto@iqm.unicamp.br
}

\section{Dedicated to Professor Edmundo A. Rúveda on his $70^{\text {th }}$ birthday and Professor Roberto A. Rossi on his $60^{\text {th }}$ birthday}

(received 12 Oct 03; accepted 24 Oct 03; published on the web 30 Oct 03)

\begin{abstract}
A study of the reduction of 2-ethyl-1-phenylprop-2-en-1-one (3) by Rhodotorula glutinis CCT 2182 in the presence and absence of XAD-7 resin is reported. The use of XAD-7 led to the corresponding $(S)$ - $\alpha$-methylketone 4 in high yield and enantiomeric excess.
\end{abstract}

Keywords: Extractive biocatalysis, asymmetric enone reduction, Amberlite XAD-7, in situ product removal

\section{Introduction}

The $\alpha$-methylketone structural moiety is present in a number of compounds including drugs and natural products, especially in pheromones. ${ }^{1}$ In most cases, the biological activity of these compounds is affected by the absolute configuration of the $\alpha$-carbon. Although it has been generally accepted that enzymatic transformations are suitable methods to obtain chiral compounds, examples of efficient regio- and enantioselective reduction of $\alpha$-methyleneketones to prepare chiral $\alpha$-methylketones are scarce. ${ }^{2}$

Biocatalytic processes are environmentally friendly in contrast to conventional chemical catalytic processes, especially when these utilize heavy-metal based catalysis. As such, biocatalysis is a highly promising field of research, especially for the development of sustainable technologies for the production of fine chemicals (green chemistry). ${ }^{3}$ As a result, biocatalysis with either isolated enzymes or whole cells has blossomed over the past few years as a viable alternative to costly or difficult chemistry in the manufacture of chiral compounds. ${ }^{4}$

In a previous study we disclosed a relationship between the structure of multiple $\alpha$ methyleneketones and the reaction profile concerning the use of baker's yeast as biocatalyst and 
reported the stereoselective synthesis of chiral $\alpha$-methylketones. ${ }^{2}$ In addition, we found that substrates, such as $\mathbf{1}$ (Scheme 1) undergo non-selective reduction by baker's yeast at the $\mathrm{C}=\mathrm{C}$ bond to afford ketone 2 , but it was unable to reduce the $\mathrm{C}=\mathrm{O}$ bond of these compounds. More recently, we have shown that the regio- and enantioselective reduction of a toxic $\alpha$ methyleneketone by the non-conventional yeast Pichia stipitis can be tuned by the use of Amberlite XAD-7 (extractive biocatalysis). ${ }^{5}$<smiles>C=C(C)C(=O)c1ccccc1</smiles>

1

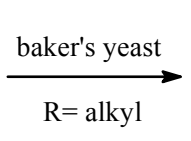

$\mathrm{R}=\mathrm{alkyl}$

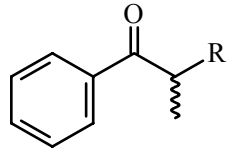

2

\section{Scheme 1}

We became interested in finding different yeasts able to circumvent the lack of enantioselectivity observed when enones of general structure 1 were reduced by baker's yeast. We wish to report that Rhodotorula glutinis CCT 2182 is able to reduce enone $\mathbf{3}$ ( $\mathrm{R}=$ ethyl) efficiently in high regio- and enantioselectivity, using Amberlite XAD-7 as adsorbing resin to control the releasing of the substrate into the aqueous phase.

\section{Results and Discussion}

\section{The effect of substrate concentration}

2-Ethyl-1-phenylpro-2-en-1-one (3) was readily prepared through a direct methylenation protocol previously described by us. ${ }^{6}$ After a small screening of yeasts (growing cells) in analytical scale, we chose Rhodororula glutinis CCT $2182(\mathrm{RG})$ as the microorganism of choice to perform the regio- and enantioselective reduction of $\mathbf{3}$ at the $\mathrm{C}=\mathrm{C}$ bond to afford ketone 4 (Scheme 2). The other yeasts evaluated, i.e. Pichia stipitis, P. canadensis, Rhodotorula minuta, Thichosporon cutaneum and Kluyveromyces marxianus, were unable to perform synthetically useful conversion of $\mathbf{3}$ probably due toxic effects. However, as it is common to many enzymatic process involving whole cells as biocatalysts, preparative scale reactions with enone $\mathbf{3}$ proved problematic due to concentration-dependent substrate toxicity to the cells of $R$. glutinis.

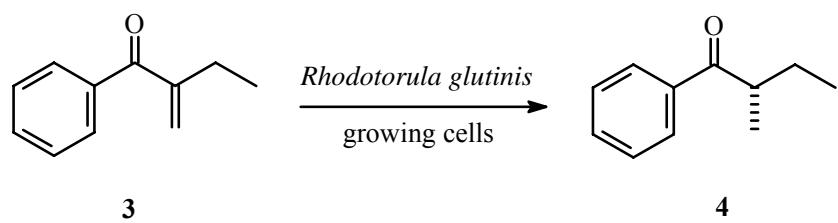

\section{Scheme 2}


We also found that the concentration of the substrate had a remarkable deleterious influence on the enantioselectivity of the reaction. Thus a direct correlation between initial substrate concentration and product enantiomeric excess was obtained by comparing different runs at different substrate concentrations. The reactions were carried out by simply adding the substrate to a slurry of $R$. glutinis. We decided to perform the experiments with resting cells of the yeast rather than growing cells as a measure to reach high cell densities in the medium and to isolate less impure products.

As shown in Figure 1, growing concentrations of enone $\mathbf{3}$ in the aqueous phase caused a significant drop in the enantiosectivity of the reaction. It is well known that unsatisfactory enantioselectivity is often the result of the simultaneous action of several enzymes, which display both different kinetics and different selectivity on the same substrate. ${ }^{7}$ Therefore, in order to achieve a more selective system it is of great importance to be able to control the reaction conditions so that the desired enzyme activity is favored and/or the undesired ones are suppressed.

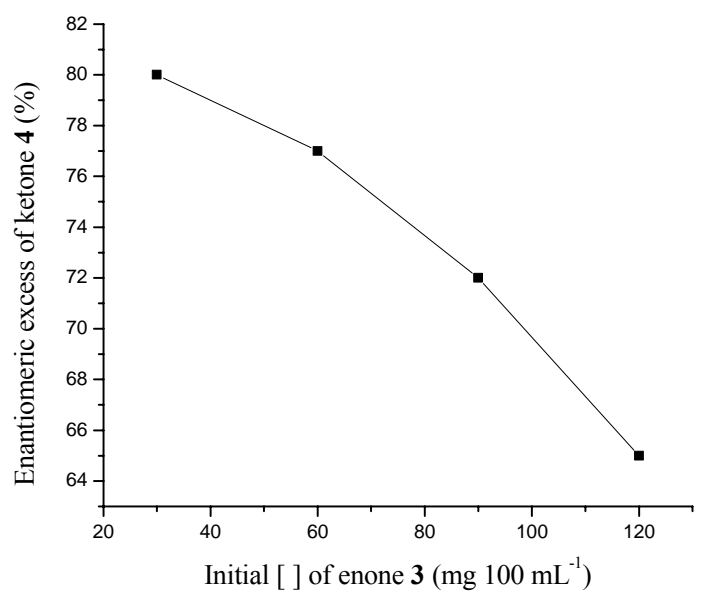

Figure 1. Effect of the initial concentration of enone $\mathbf{3}$ on the enantiomeric excess of ketone 4 after $3 \mathrm{~h}$ incubation with $R$. glutinis $\left(28{ }^{\circ} \mathrm{C}, 100 \mathrm{~mL}\right.$ distilled water, $4.5 \mathrm{~g}$ RG wet weight, $4.5 \mathrm{~g}$ glucose, $150 \mathrm{rpm})$.

\section{The effect of Amberlite XAD-7}

Since the decreased substrate concentration in a multienzymatic system favors the reaction catalyzed by the enzyme with the lower $\mathrm{Km}$ for the substrate, the control of substrate concentration will ultimately influence the enantiomeric excess of the product. ${ }^{8}$ Hitherto the strategy of adsorbing the substrate onto a hydrophobic polymer (e.g. Amberlite XAD-7) proved to be a unique approach to control the concentration of both substrate and product in the aqueous phase. $5,7,8$

We have recently shown that the use of XAD-7 was crucial to ensure the efficient and selective reduction of enone $\mathbf{3}$ by the yeast Pichia stipitis to afford a chiral allylic alcohol. ${ }^{5}$ The 
XAD-7 resin adsorbs the hydrophobic substrate and decreases its concentration in the aqueous phase. This low concentration drove the reaction to completion and a single product was obtained with high regio- and enantioselectivity.

Figure 2 shows the effect of XAD-7 on the stereochemical course of the reduction of enone 3 by Rhodotorula glutinis. Increasing amounts of XAD-7 increased the enantioselectivity of the reaction. The best enantiomeric excess for ketone 4 (99\%) was achieved by adsorbing the enone 3 (150 mg) onto $3 \mathrm{~g}$ of XAD-7. Since the resin does not interfere in other ways with the reaction medium, the observed increased enantioselectivity must be attributed to the reduced concentration of the substrate in the aqueous phase.

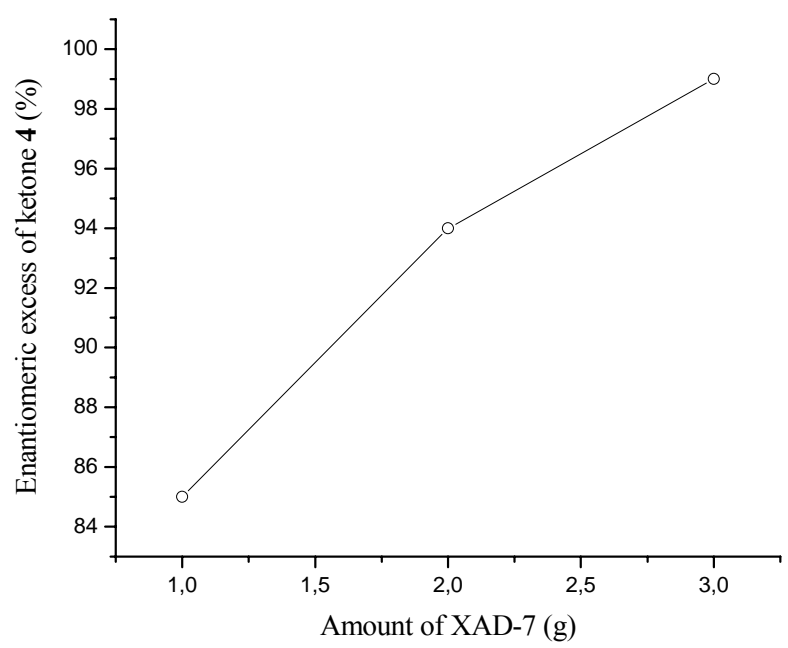

Figure 2. Effect of the amount of XAD-7 on the enantiomeric excess of ketone 4 after 3 days incubation of enone $3(150 \mathrm{mg})$ with $R$. glutinis $\left(28^{\circ} \mathrm{C}, 100 \mathrm{~mL}\right.$ distilled water, $4.5 \mathrm{~g}$ RG wet weight, $4.5 \mathrm{~g}$ glucose, $150 \mathrm{rpm})$.

The absolute configuration of ketone 4 was established as $S$ by comparison of the specific optical rotation $[\alpha]_{\mathrm{D}}$ found with that previously reported. ${ }^{9}$ Thus, the $S$-enzyme(s) which is assumed to have a smaller $K \mathrm{~m}$ value to the enone than that of the R-enzyme(s), contributes predominantly to the reduction.

The yield of ketone 4, recovered from the aqueous medium by the beads of XAD-7, was also dependent on the amount of resin used (Figure 3). The product is progressively extracted with increasing amounts of XAD-7. This shows that XAD-7 can be profitably used in controlling the substrate concentration and hence the enantioselectivity and yield of reduction of enone 3 by $R$. glutinis. However, this low concentration in the aqueous phase imparted a low rate of conversion of enone 3 by the yeast: a 3 days incubation period was required to reach total consumption of the substrate.

These results are important clues to understanding the enzyme activity. Since inhibitory effects cannot be claimed in this case, the $S$-enzyme(s) that remains catalytically active at low concentrations of $\mathbf{3}$ is not acting in its full catalytic activity probably because the concentration 
of $\mathbf{3}$ in the aqueous phase is by far lower than the Km of the enzyme(s). As a consequence more time is required to biotransform the substrate.

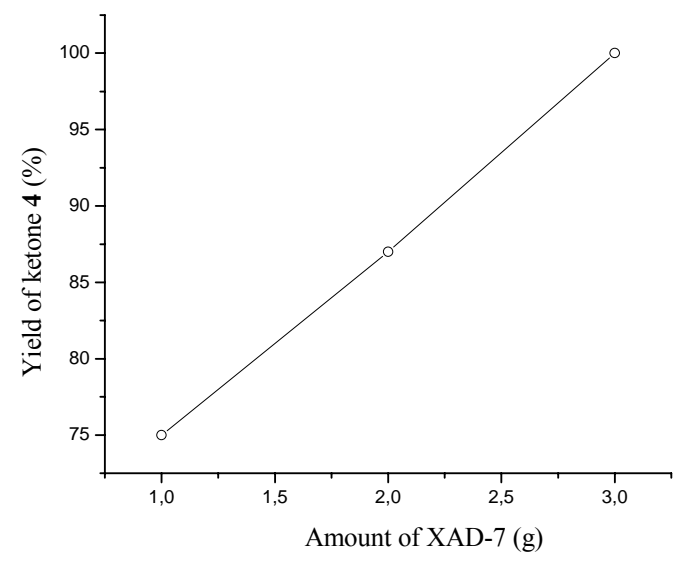

Figure 3. Ketone 4 recovery from XAD-7 beads after 3 days incubation of enone 3 (150 mg) with $R$. glutinis $\left(28^{\circ} \mathrm{C}, 100 \mathrm{~mL}\right.$ distilled water, $4.5 \mathrm{~g}$ RG wet weight, $4.5 \mathrm{~g}$ glucose, $\left.150 \mathrm{rpm}\right)$, as a function of the amount of XAD-7.

In conclusion, the hydrophobic polymer method used here is based on the fact that an adsorbed hydrophobic substrate (3) is partitioned into the solid phase (XAD-7) and the aqueous phase. The substrate being largely in the solid phase. XAD-7 acts as a reservoir of $\mathbf{3}$, supplying by equilibrium process the amount consumed by the biocatalyst in the aqueous phase. In turn, the product (4) released by the biocatalyst in the aqueous phase is extracted in situ by XAD-7, preventing its accumulation in the aqueous phase. With the present study, a practical regiocomplementary approach is available for the asymmetric reduction of enone $\mathbf{3}$ by just selecting a suitable yeast and conditions to perform the reduction process (Scheme 3 ).
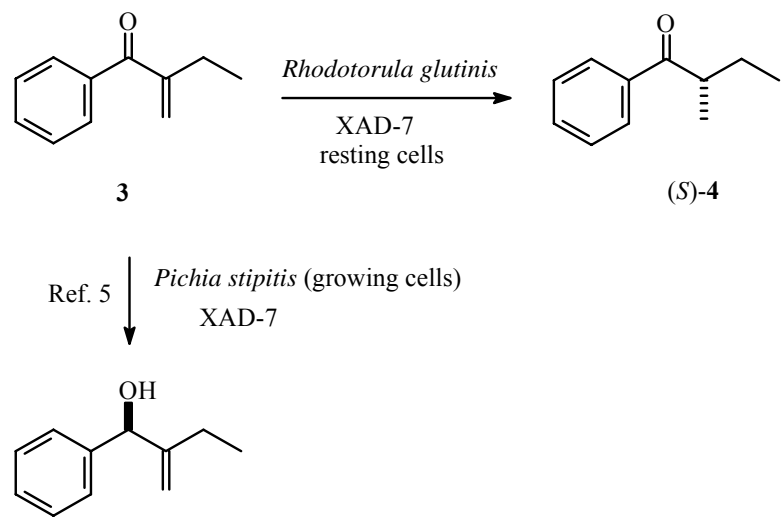

$(S)-5$

\section{Scheme 3}




\section{Experimental Section}

General Procedures. ${ }^{1} \mathrm{H}$ and ${ }^{13} \mathrm{C}$ NMR spectra were recorded on an INOVA-500 or Varian Gemini 300P spectrometer. Optical rotations were measured on a JASCO J-720 spectropolarimeter. CD spectra were recorded on a JASCO J-720 spectropolarimeter. GC/MS analysis were performed on a Shimadzu QP-5000 instrument equipped with a Supelco Simplicity 1 fused silica capillary column ( $30 \mathrm{~m} \times 0.25 \mathrm{~mm} \times 0.25 \mu \mathrm{m})$ or a Chirasil-Dex fused silica capillary chiral column $(30 \mathrm{~m} \times 0.25 \mathrm{~mm} \times 0.25 \mu \mathrm{m})$ with Helium as carrier gas $\left(1.3 \mathrm{~mL} \mathrm{~min}^{-1}\right)$. The strain of R. glutinis (CCT 2182) is stored at "André Tosello" Research Foundation (Brazil). Bactopeptone, yeast extract and malt extract were purchased from Biobrás (Brazil). All solvents and reagents were commercially available (reagent grade) and were used without further purification.

\section{Growth conditions of Rhodotorula glutinis}

R. glutinis CCT 2182 was cultivated in YM (yeast-malt extract) nutrient broth $(1 \mathrm{~L})$ under aseptic conditions for 2 days incubation at $28{ }^{\circ} \mathrm{C}$ on an orbital shaker $(150 \mathrm{rpm})$ before use. Alternatively, the cells were harvested by centrifugation ( $5000 \mathrm{rpm}, 5 \mathrm{~min})$.

\section{General procedure for biotransformation of enone 3}

Effect of the substrate. To a slurry of $R$. glutinis CCT 2182 (4.5 g, wet weight) and glucose $(4.5 \mathrm{~g})$, in sterile distilled water $(100 \mathrm{~mL})$, a solution of enone $3(30,60,90$ or $120 \mathrm{mg})$ in ethanol $(0.5 \mathrm{~mL})$ was added. The resulting suspension was stirred on an orbital shaker $(150 \mathrm{rpm})$ at $28{ }^{\circ} \mathrm{C}$ until the full consumption of 3 (3 hours), as indicated by CG/MS analysis. The enantiomeric excess (\%) of ketone 4 was as follows: $30 \mathrm{mg}$ (80), $60 \mathrm{mg}$ (77), $90 \mathrm{mg}$ (72) and $120 \mathrm{mg}(65)$.

\section{Effect of Amberlite XAD-7}

Commercially available resin XAD-7 was successively washed with distilled water and acetone and then dried under reduced pressure. The substrate $3(150 \mathrm{mg})$ was diluted in acetone and added to different amounts of the treated XAD-7 (1, 2 or $3 \mathrm{~g})$. The mixture was shaken and the solvent was evaporated to dryness at reduced pressure. The solid so obtained was poured directly into the slurry of $R$. glutinis described above. The resulting suspension was stirred on an orbital shaker (150 rpm) at $28{ }^{\circ} \mathrm{C}$ until the full consumption of $\mathbf{3}$ (ca. 3 days), as indicated by CG/MS analysis. Solvent removal followed by purification (flash column chromatography, hexane/ethyl acetate 4:1) afforded ketone 4: $1 \mathrm{~g}$ XAD-7 (114 mg, 75\% yield, 85\% e.e.), 2 g XAD-7 (132 mg, $87 \%$ yield, 94\% e.e.) and $3 \mathrm{~g} \mathrm{XAD}-7$ (150 mg, 99\% yield, 99\% e.e.). Spectroscopic data for ketone $\mathbf{4}$ were in agreement with those previously reported. ${ }^{2 \mathrm{a}}$

Ketone 4 isolated in the experiment with $3 \mathrm{~g} \mathrm{XAD}-7$ was used to record the $\mathrm{CD}$ spectrum and to measure the specific optical rotation: $[\alpha]_{\mathrm{D}}^{20}=+52\left(c 1, \mathrm{CHCl}_{3}\right)$ and $[\alpha]_{\mathrm{D}}^{20}=+23\left(c \quad 0.64, \mathrm{Et}_{2} \mathrm{O}\right)$, Lit. ${ }^{9}:[\alpha]_{\mathrm{D}}^{20}=+36.8\left(c 0.64, \mathrm{Et}_{2} \mathrm{O}\right)$. 


\section{Acknowledgements}

Financial support from the Brazilian agencies FAPESP and CNPq is gratefully acknowledged.

\section{References}

1. Loughlin, W. A. Bioresour. Technol. 2000, 74, 49.

2. (a) Siqueira-Filho, E. P.; Moran, P. J. S.; Rodrigues, J. A. R. Tetrahedron: Asymmetry 2001, 12, 847. (b) Siqueira-Filho, E. P.; Moran, P. J. S.; Rodrigues, J. A. R. J. Mol. Catal. B: Enzym. 2001, 15, 23 and references cited therein.

3. Anastas, P. T.; Kirchhoff, M. M. Acc. Chem. Res. 2002, 35, 686.

4. (a) For a recent review, see: Patel R.; Hanson R.; Goswami A.; Nanduri V.; Banerjee A.; Donovan M. J.; Goldberg S.; Johnston R.; Brzozowski D.; Tully T.; Howell J.; Cazzulino D.; Ko R. J. Ind. Microbiol. Biotech. 2003, 30, 252. (b) De Conti, R.; Rodrigues, J. A. R.; Moran, P. J. S. Quim. Nova 2001, 24, 672.

5. Conceição, G. J. A.; Moran, P. J. S.; Rodrigues, J. A. R. Tetrahedron: Asymmetry 2003, 14, 43.

6. Rodrigues, J. A. R.; Siqueira-Filho, E. P.; Mancilha, M.; Moran, P. J. S. Synth. Commun. 2003, 33, 333.

7. D'Arrigo, P.; Fantoni, G. P.; Servi, S.; Strini, A. Tetrahedron: Asymmetry 1997, 8, 2375.

8. D’Arrigo, P.; Fuganti, C.; Fantoni, G. P.; Servi, S. Tetrahedron 1998, 54, 15017.

9. Oppolzer, W.; Darcel, C.; Rochet, P.; Rosset, S.; De Brabander, J. Helv. Chim. Acta 1997, 80, 1319. 